\title{
Papers
}

\section{Dietary fat intake and risk of stroke in male US healthcare professionals: 14 year prospective cohort study}

Ka He, Anwar Merchant, Eric B Rimm, Bernard A Rosner, Meir J Stampfer, Walter C Willett, Alberto Ascherio

\begin{abstract}
Objective To examine the association between intake of total fat, specific types of fat, and cholesterol and risk of stroke in men.

Design and setting Health professional follow up study with 14 year follow up.

Participants 43732 men aged 40-75 years who were free from cardiovascular diseases and diabetes in 1986. Main outcome measure Relative risk of ischaemic and haemorrhagic stroke according to intake of total fat, cholesterol, and specific types of fat.

Results During the 14 year follow up 725 cases of stroke occurred, including 455 ischaemic strokes, 125 haemorrhagic stokes, and 145 strokes of unknown type. After adjustment for age, smoking, and other potential confounders, no evidence was found that the amount or type of dietary fat affects the risk of developing ischaemic or haemorrhagic stroke. Comparing the highest fifth of intake with the lowest fifth, the multivariate relative risk of ischaemic stroke was $0.91(95 \%$ confidence interval 0.65 to 1.28 ; $\mathrm{P}$ for trend $=0.77)$ for total fat, $1.20(0.84$ to $1.70 ; \mathrm{P}=0.47)$ for animal fat, 1.07 ( 0.77 to $1.47 ; \mathrm{P}=0.66)$ for vegetable fat, $1.16(0.81$ to $1.65 ; \mathrm{P}=0.59)$ for saturated fat, 0.91 ( 0.65 to $1.28 ; \mathrm{P}=0.83)$ for monounsaturated fat, $0.88(0.64$ to $1.21 ; \mathrm{P}=0.25)$ for polyunsaturated fat, 0.87 (0.62 to $1.22 ; \mathrm{P}=0.42)$ for trans unsaturated fat, and 1.02 ( 0.75 to $1.39 ; \mathrm{P}=0.99)$ for dietary cholesterol. Intakes of red meats, high fat dairy products, nuts, and eggs were also not appreciably related to risk of stroke.

Conclusions These findings do not support associations between intake of total fat, cholesterol, or specific types of fat and risk of stroke in men.
\end{abstract}

\section{Introduction}

Strong evidence indicates that type of dietary fat is more important than total fat intake in predicting risk of coronary heart disease, as different types of fat or fatty acids may play different or opposite roles. Monounsaturated and polyunsaturated fats seem to have beneficial effects, but saturated fat and trans unsaturated fatty acids increase risk of coronary heart disease. ${ }^{1}$ However, these associations do not seem to apply to stroke. Previous studies have even suggested an inverse relation between saturated fat or trans unsaturated fat intake and risk of stroke, ${ }^{23}$ but the mechanisms remain unclear. Although epidemiological studies indicated beneficial effects of some specific fatty acids such as long chain omega 3 polyunsaturated fatty acid, $\alpha$ linolenic acid, and linoleic acid on ischaemic stroke, ${ }^{4-6}$ few studies have directly related intake of dietary fat to risks of subtypes of stroke, and the results have been inconsistent. We prospectively examined the associations between intakes of total fat and specific types of fat and the risk of subtypes of stroke in the health professional follow up study.

\section{Methods}

\section{Study population}

The health professional follow up study is a cohort of 51529 male US healthcare professionals, aged 40-75 years in 1986, who responded to a mailed questionnaire including a comprehensive survey of diet, lifestyle characteristics, and medical history. Non-dietary variables are updated every other year and dietary information every four years. For this analysis, we followed participants from 1986 to 2000 . We excluded men who at baseline reported a previous diagnosis of cardiovascular diseases or diabetes mellitus. We also excluded men who had incomplete information ( $\geq 70$ blanks out of 131 listed food items) or implausible total daily energy intake ( $\leq 800$ or $\geq 4200 \mathrm{kcal}(\leq 3.34$ or $\geq 17.56 \mathrm{MJ})$. A total of 43732 men remained in the analyses. The response to the questionnaires constituted the participants' informed consent

\section{Dietary assessment}

We assessed dietary intake by using semiquantitative food frequency questionnaires in 1986, 1990, and 1994. ${ }^{7}$ We asked participants to record the frequency of consumption of specified portions of each selected food during the previous year by using one of nine options ranging from "never or $<1 /$ month" to " $\geq 6$ /day." We also inquired about types of fat, oil, or margarine used in food preparation and at the table. We obtained values for the amounts of nutrients, including specific types of fat, in foods from the Harvard University food composition database, which was updated over time with data from the US Department of Agriculture, manufacturers, and published reports. We based values for total trans isomer contents in food in part on analyses by Enig et al and Slover
Department of Nutrition, Harvard School of Public Health, 665 Huntington Avenue, Boston, MA 02115, USA $\mathrm{Ka} \mathrm{He}$

research associate Anwar Merchant research associate Eric B Rimm associate professor Meir J Stampfer professor

Walter C Willett professor

Alberto Ascherio associate professor

Department of Biostatistics,

Harvard School of Public Health Bernard A Rosner professor

Correspondence to: $\mathrm{K} \mathrm{He}$ hpkhe@channing. harvard.edu

bmj.com 2003:327:777 
et al. ${ }^{8}$ To assess the effects of food groups rich in fat or cholesterol, we defined red meat as beef, pork, or lamb as a main dish; beef, pork, or lamb as a sandwich or mixed dish; hamburgers; hot dogs; processed meat; and bacon. We defined high fat dairy food as whole milk, ice cream, hard cheese, butter, and sour cream.
The validity of the food frequency questionnaire has been evaluated in a subcohort. After adjustment for energy and de-attenuation for within person variation, the Pearson correlation between the questionnaire and the average of two single week diet records six months apart was 0.67 for total fat, 0.75 for

Table 1 Relative risks of stroke ( $95 \%$ confidence intervals) according to fifths of total fat, specific types of fat, dietary cholesterol, and Keys score

\begin{tabular}{|c|c|c|c|c|c|c|}
\hline & \multicolumn{5}{|c|}{ Fifths of nutrient intake } & \multirow[b]{2}{*}{ P for trend } \\
\hline & 1 & 2 & 3 & 4 & 5 & \\
\hline \multicolumn{7}{|l|}{ Total fat } \\
\hline Median intake (g/day) & 54 & 64 & 70 & 77 & 86 & - \\
\hline \multicolumn{7}{|l|}{ Ischaemic stroke: } \\
\hline No of cases & 89 & 87 & 91 & 97 & 91 & - \\
\hline Adjusted for age and smoking & 1.0 & 0.96 (0.72 to 1.29$)$ & $0.97(0.72$ to 1.30$)$ & 1.04 (0.78 to 1.39$)$ & 0.93 (0.68 to 1.25$)$ & 0.91 \\
\hline Multivariate $^{*}$ & 1.0 & 0.93 (0.68 to 1.26$)$ & $1.02(0.74$ to 1.39$)$ & $1.02(0.74$ to 1.42$)$ & 0.91 (0.65 to 1.28$)$ & 0.77 \\
\hline \multicolumn{7}{|l|}{ Haemorrhagic stroke: } \\
\hline No of cases & 18 & 30 & 28 & 23 & 26 & - \\
\hline Adjusted for age and smoking & 1.0 & 1.66 (0.93 to 2.98$)$ & 1.50 (0.83 to 2.71$)$ & $1.23(0.66$ to 2.30$)$ & 1.32 (0.71 to 2.45$)$ & 0.73 \\
\hline Multivariate* $^{*}$ & 1.0 & 1.76 (0.95 to 3.25$)$ & 1.49 (0.79 to 2.83$)$ & 1.18 (0.60 to 2.35$)$ & 1.16 (0.58 to 2.32$)$ & 0.83 \\
\hline \multicolumn{7}{|l|}{ Animal fat } \\
\hline Median intake (g/day) & 25 & 33 & 39 & 45 & 54 & - \\
\hline \multicolumn{7}{|l|}{ Ischaemic stroke: } \\
\hline No of cases & 80 & 90 & 95 & 88 & 102 & - \\
\hline Adjusted for age and smoking & 1.0 & 1.07 (0.78 to 1.45$)$ & 1.13 (0.84 to 1.53$)$ & 1.05 (0.77 to 1.43$)$ & 1.16 (0.86 to 1.58$)$ & 0.55 \\
\hline Multivariate $^{*}$ & 1.0 & 1.14 (0.83 to 1.56$)$ & $1.12(0.81$ to 1.55$)$ & $1.04(0.74$ to 1.46$)$ & 1.20 (0.84 to 1.70$)$ & 0.47 \\
\hline+ vegetable fat† & 1.0 & 1.11 (0.81 to 1.53$)$ & 1.10 (0.79 to 1.52$)$ & $1.02(0.72$ to 1.44$)$ & 1.15 (0.80 to 1.65$)$ & 0.61 \\
\hline \multicolumn{7}{|l|}{ Haemorrhagic stroke: } \\
\hline No of cases & 21 & 21 & 25 & 35 & 23 & - \\
\hline Adjusted for age and smoking & 1.0 & 0.95 (0.52 to 1.77$)$ & 1.14 (0.63 to 2.06$)$ & 1.61 (0.92 to 2.82) & 1.01 (0.54 to 1.90$)$ & 0.45 \\
\hline Multivariate $^{*}$ & 1.0 & 0.95 (0.50 to 1.79$)$ & 1.12 (0.60 to 2.10$)$ & 1.49 (0.80 to 2.78$)$ & 0.90 (0.45 to 1.81$)$ & 0.90 \\
\hline+ vegetable fat $†$ & 1.0 & 0.92 (0.49 to 1.74$)$ & 1.08 (0.58 to 2.04$)$ & 1.44 (0.77 to 2.70$)$ & 0.86 (0.42 to 1.77$)$ & 0.99 \\
\hline \multicolumn{7}{|l|}{ Vegetable fat } \\
\hline Median intake (g/day) & 20 & 26 & 30 & 34 & 42 & - \\
\hline \multicolumn{7}{|l|}{ Ischaemic stroke: } \\
\hline No of cases & 94 & 105 & 96 & 70 & 90 & - \\
\hline Adjusted for age and smoking & 1.0 & 1.18 (0.89 to 1.56$)$ & $1.11(0.83$ to 1.47$)$ & $0.82(0.60$ to 1.12$)$ & 0.98 (0.74 to 1.31$)$ & 0.27 \\
\hline Multivariate $^{*}$ & 1.0 & 1.22 (0.91 to 1.62$)$ & $1.23(0.91$ to 1.66$)$ & $0.83(0.60$ to 1.16$)$ & 1.07 (0.77 to 1.47$)$ & 0.66 \\
\hline + animal fat† & 1.0 & 1.22 (0.91 to 1.62$)$ & 1.24 (0.92 to 1.67) & $0.84(0.60$ to 1.18$)$ & 1.09 (0.78 to 1.51$)$ & 0.79 \\
\hline \multicolumn{7}{|l|}{ Haemorrhagic stroke: } \\
\hline No of cases & 25 & 23 & 27 & 27 & 23 & - \\
\hline Adjusted for age and smoking & 1.0 & 0.96 (0.54 to 1.69$)$ & $1.16(0.68$ to 2.00$)$ & 1.17 (0.68 to 2.04) & 0.95 (0.53 to 1.69$)$ & 0.83 \\
\hline Multivariate* $^{*}$ & 1.0 & 1.01 (0.56 to 1.82$)$ & 1.20 (0.68 to 2.13 ) & 1.25 (0.70 to 2.25$)$ & 0.87 (0.46 to 1.63$)$ & 0.80 \\
\hline+ animal fat & 1.0 & $1.00(0.56$ to 1.80$)$ & 1.20 (0.67 to 2.13 ) & 1.24 (0.68 to 2.24) & 0.86 (0.45 to 1.64$)$ & 0.80 \\
\hline \multicolumn{7}{|l|}{ Saturated fat } \\
\hline Median intake (g/day) & 17 & 21 & 24 & 26 & 31 & - \\
\hline \multicolumn{7}{|l|}{ Ischaemic stroke: } \\
\hline No of cases & 81 & 92 & 95 & 88 & 99 & - \\
\hline Adjusted for age and smoking & 1.0 & 1.10 (0.82 to 1.49$)$ & $1.15(0.86$ to 1.54$)$ & 1.01 (0.75 to 1.38$)$ & 1.08 (0.80 to 1.46$)$ & 0.65 \\
\hline Multivariate $^{*}$ & 1.0 & $1.16(0.85$ to 1.59$)$ & 1.19 (0.86 to 1.65$)$ & 1.08 (0.77 to 1.52$)$ & 1.16 (0.81 to 1.65$)$ & 0.59 \\
\hline + poly, mono, trans $\dagger$ & 1.0 & 1.24 (0.87 to 1.76$)$ & 1.26 (0.84 to 1.88$)$ & 1.13 (0.73 to 1.76$)$ & 1.21 (0.75 to 1.97$)$ & 0.63 \\
\hline \multicolumn{7}{|l|}{ Haemorrhagic stroke: } \\
\hline No of cases & 18 & 24 & 34 & 26 & 23 & - \\
\hline Adjusted for age and smoking & 1.0 & 1.30 (0.71 to 2.39 ) & 1.86 (1.05 to 3.31$)$ & 1.36 (0.73 to 2.54$)$ & 1.15 (0.60 to 2.19$)$ & 0.63 \\
\hline Multivariate $^{*}$ & 1.0 & 1.27 (0.66 to 2.42$)$ & 1.74 (0.93 to 3.26$)$ & 1.34 (0.68 to 2.66) & 0.99 (0.48 to 2.04$)$ & 0.85 \\
\hline+ poly, mono, trans $\dagger$ & 1.0 & 1.30 (0.64 to 2.64$)$ & $1.93(0.91$ to 4.08$)$ & 1.56 (0.67 to 3.67$)$ & 1.17 (0.45 to 3.07$)$ & 0.83 \\
\hline \multicolumn{7}{|l|}{ Monounsaturated fat } \\
\hline Median intake (g/day) & 20 & 24 & 27 & 30 & 34 & - \\
\hline \multicolumn{7}{|l|}{ Ischaemic stroke: } \\
\hline No of cases & 90 & 82 & 91 & 99 & 93 & - \\
\hline Adjusted for age and smoking & 1.0 & 0.88 (0.65 to 1.18$)$ & 0.99 (0.74 to 1.33) & $1.06(0.80$ to 1.41$)$ & 0.88 (0.66 to 1.19$)$ & 0.96 \\
\hline Multivariate $^{*}$ & 1.0 & 0.89 (0.65 to 1.21$)$ & 1.03 (0.75 to 1.42$)$ & $1.03(0.74$ to 1.42$)$ & 0.91 (0.65 to 1.28$)$ & 0.83 \\
\hline + poly, sat, trans $\dagger$ & 1.0 & 0.85 (0.59 to 1.22$)$ & 1.01 (0.67 to 1.53) & 1.06 (0.67 to 1.68) & 1.00 (0.58 to 1.70$)$ & 0.85 \\
\hline Haemorrhagic stroke: & & & & & & \\
\hline No of cases & 22 & 27 & 25 & 23 & 28 & - \\
\hline Adjusted for age and smoking & 1.0 & 1.22 (0.70 to 2.15$)$ & 1.14 (0.64 to 2.02) & 1.04 (0.57 to 1.87$)$ & 1.14 (0.64 to 2.03$)$ & 0.82 \\
\hline Multivariate $^{*}$ & 1.0 & 1.23 (0.68 to 2.22$)$ & 1.00 (0.54 to 1.88$)$ & 0.91 (0.47 to 1.75$)$ & 0.95 (0.49 to 1.83$)$ & 0.62 \\
\hline+ poly, sat, trans $\dagger$ & 1.0 & 0.96 (0.48 to 1.93$)$ & 0.69 (0.30 to 1.56$)$ & 0.61 (0.24 to 1.55$)$ & 0.68 (0.24 to 1.96$)$ & 0.40 \\
\hline
\end{tabular}


Table 1 Relative risks of stroke (95\% confidence intervals) according to fifths of total fat, specific types of fat, dietary cholesterol, and Keys score contd

\begin{tabular}{|c|c|c|c|c|c|c|}
\hline & \multicolumn{5}{|c|}{ Fifths of nutrient intake } & \multirow[b]{2}{*}{$P$ for trend } \\
\hline & 1 & 2 & 3 & 4 & 5 & \\
\hline \multicolumn{7}{|l|}{ Polyunsaturated fat } \\
\hline Median intake (g/day) & 10 & 11 & 13 & 14 & 17 & - \\
\hline \multicolumn{7}{|l|}{ Ischaemic stroke: } \\
\hline No of cases & 96 & 101 & 92 & 89 & 77 & - \\
\hline Adjusted for age and smoking & 1.0 & $1.13(0.85$ to 1.50$)$ & $1.04(0.78$ to 1.39$)$ & $1.03(0.77$ to 1.38$)$ & 0.88 (0.65 to 1.19$)$ & 0.28 \\
\hline Multivariate* $^{\star}$ & 1.0 & 1.14 (0.85 to 1.53$)$ & $1.11(0.82$ to 1.49$)$ & 0.99 (0.73 to 1.34$)$ & 0.88 (0.64 to 1.21$)$ & 0.25 \\
\hline + mono, sat, trans $\dagger$ & 1.0 & 1.15 (0.85 to 1.55$)$ & 1.11 (0.81 to 1.53$)$ & $0.98(0.70$ to 1.37$)$ & 0.86 (0.59 to 1.25$)$ & 0.26 \\
\hline \multicolumn{7}{|l|}{ Haemorrhagic stroke: } \\
\hline No of cases & 27 & 22 & 28 & 25 & 23 & - \\
\hline Adjusted for age and smoking & 1.0 & 0.87 (0.50 to 1.52$)$ & $1.14(0.67$ to 1.93$)$ & $1.00(0.58$ to 1.73$)$ & 0.92 (0.53 to 1.59 ) & 0.97 \\
\hline Multivariate* & 1.0 & 0.85 (0.47 to 1.52$)$ & $1.12(0.64$ to 1.96$)$ & 1.02 (0.57 to 1.82$)$ & 0.86 (0.47 to 1.56$)$ & 0.75 \\
\hline + mono, sat, trans $\dagger$ & 1.0 & 0.89 (0.49 to 1.64$)$ & $1.20(0.66$ to 2.19$)$ & 1.09 (0.57 to 2.09$)$ & 0.95 (0.46 to 1.98$)$ & 0.99 \\
\hline \multicolumn{7}{|l|}{ Trans unsaturated fat } \\
\hline Median intake (g/day) & 1.67 & 2.34 & 2.86 & 3.44 & 4.42 & - \\
\hline \multicolumn{7}{|l|}{ Ischaemic stroke: } \\
\hline No of cases & 91 & 93 & 83 & 97 & 91 & - \\
\hline Adjusted for age and smoking & 1.0 & 1.01 (0.76 to 1.35$)$ & 0.90 (0.67 to 1.22$)$ & $1.10(0.83$ to 1.45$)$ & 0.93 (0.69 to 1.25$)$ & 0.79 \\
\hline Multivariate* ${ }^{*}$ & 1.0 & 1.01 (0.75 to 1.37$)$ & 0.86 (0.62 to 1.19$)$ & 0.98 (0.71 to 1.35$)$ & 0.87 (0.62 to 1.22$)$ & 0.42 \\
\hline + poly, mono, sat† & 1.0 & 0.96 (0.70 to 1.33$)$ & 0.80 (0.57 to 1.14$)$ & $0.90(0.63$ to 1.29$)$ & 0.80 (0.54 to 1.17$)$ & 0.26 \\
\hline \multicolumn{7}{|l|}{ Haemorrhagic stroke: } \\
\hline No of cases & 18 & 29 & 22 & 22 & 34 & - \\
\hline Adjusted for age and smoking & 1.0 & 1.66 (0.93 to 2.97$)$ & $1.20(0.63$ to 2.26$)$ & $1.24(0.66$ to 2.31$)$ & 1.78 (0.99 to 3.19$)$ & 0.16 \\
\hline Multivariate* & 1.0 & 1.54 (0.83 to 2.87 ) & 1.16 (0.59 to 2.27$)$ & 1.06 (0.53 to 2.15$)$ & 1.76 (0.90 to 3.45$)$ & 0.20 \\
\hline + poly, mono, sat $\dagger$ & 1.0 & 1.44 (0.76 to 2.73$)$ & $1.13(0.55$ to 2.30$)$ & 1.11 (0.53 to 2.36$)$ & 1.90 (0.90 to 3.98$)$ & 0.13 \\
\hline \multicolumn{7}{|l|}{ Cholesterol } \\
\hline Median intake (mg/d) & 189 & 239 & 278 & 321 & 398 & - \\
\hline \multicolumn{7}{|l|}{ Ischaemic stroke: } \\
\hline No of cases & 87 & 81 & 85 & 89 & 113 & - \\
\hline Adjusted for age and smoking & 1.0 & 0.90 (0.67 to 1.23$)$ & 0.90 (0.67 to 1.22$)$ & $0.89(0.65$ to 1.20$)$ & 1.06 (0.79 to 1.41$)$ & 0.72 \\
\hline Multivariate* & 1.0 & 0.97 (0.72 to 1.32 ) & 0.85 (0.62 to 1.16$)$ & $0.82(0.60$ to 1.13$)$ & 1.02 (0.75 to 1.39$)$ & 0.99 \\
\hline + poly, mono, sat, trans $\dagger$ & 1.0 & 0.93 (0.68 to 1.27$)$ & $0.80(0.57$ to 1.10$)$ & 0.76 (0.54 to 1.06$)$ & $0.93(0.66$ to 1.30$)$ & 0.63 \\
\hline \multicolumn{7}{|l|}{ Haemorrhagic stroke: } \\
\hline No of cases & 24 & 19 & 25 & 24 & 33 & - \\
\hline Adjusted for age and smoking & 1.0 & 0.77 (0.42 to 1.38$)$ & 0.95 (0.55 to 1.65$)$ & $0.82(0.46$ to 1.44$)$ & $1.10(0.66$ to 1.86$)$ & 0.51 \\
\hline Multivariate* & 1.0 & 0.70 (0.37 to 1.32$)$ & $1.02(0.57$ to 1.83$)$ & 0.91 (0.50 to 1.65$)$ & 1.04 (0.58 to 1.88$)$ & 0.61 \\
\hline + poly, mono, sat, trans $\dagger$ & 1.0 & 0.66 (0.34 to 1.26$)$ & 0.99 (0.54 to 1.82$)$ & $0.90(0.48$ to 1.70$)$ & 1.16 (0.61 to 2.20$)$ & 0.37 \\
\hline \multicolumn{7}{|l|}{ Keys scoreł } \\
\hline Median score & 27.0 & 33.1 & 37.0 & 41.0 & 47.4 & - \\
\hline \multicolumn{7}{|l|}{ Ischaemic stroke: } \\
\hline No of cases & 86 & 84 & 88 & 91 & 106 & - \\
\hline Adjusted for age and smoking & 1.0 & 0.93 (0.69 to 1.25$)$ & $0.99(0.73$ to 1.33$)$ & $0.97(0.72$ to 1.30$)$ & 1.04 (0.77 to 1.39$)$ & 0.66 \\
\hline Multivariate ${ }^{*}$ & 1.0 & $0.92(0.67$ to 1.26$)$ & 0.96 (0.69 to 1.33$)$ & 0.96 (0.69 to 1.34$)$ & 1.04 (0.74 to 1.48$)$ & 0.71 \\
\hline \multicolumn{7}{|l|}{ Haemorrhagic stroke: } \\
\hline No of cases & 19 & 21 & 28 & 33 & 24 & - \\
\hline Adjusted for age and smoking & 1.0 & 1.04 (0.55 to 1.94$)$ & 1.48 (0.83 to 2.65$)$ & 1.64 (0.92 to 2.92$)$ & 1.00 (0.52 to 1.92$)$ & 0.40 \\
\hline Multivariate* & 1.0 & $1.12(0.58$ to 2.15$)$ & $1.46(0.77$ to 2.76$)$ & 1.59 (0.84 to 3.02$)$ & 1.07 (0.53 to 2.19$)$ & 0.68 \\
\hline
\end{tabular}

Poly=polyunsaturated fat; mono=monounsaturated fat; sat=saturated fat; trans=trans unsaturated fat. ${ }^{*}$ Adjusted for body mass index (<21, 21-22.9, 23-24.9, 25-29.9, or $\geq 30$ ), physical activity (fifths), history of hypertension (yes or no), smoking status (never, past, and current with $1-14,15-24$,
or $\geq 25$ cigarettes/day), aspirin use (yes or no), multivitamin use (yes or no), and consumption of alcohol (0, 0.1-9.9, 10-19.9, 20-29.9, or $\geq 30 \mathrm{~g} /$ day), potassium (fifths), fibre (fifths), and vitamin E (fifths), total servings of fruit and vegetables (fifths), total energy intake (continuous), and hypercholesterolaemia (yes or no) at baseline.

†Additional adjustments. All additional variables are fifths.

łKeys score=1.26(2S-P)+1.5(square root $(\mathrm{C}))$; $\mathrm{S}=$ percentages of total energy from saturated fat; $\mathrm{P}=$ percentages of total energy from polyunsaturated fat; $\mathrm{C}=$ daily cholesterol intake in mg/1000 kcal.

saturated fat, 0.37 for polyunsaturated fat, 0.68 for monounsaturated fat, and 0.76 for cholesterol. ${ }^{10}$ In addition, a Spearman correlation of 0.34 was obtained for the comparison of intake of trans unsaturated fatty acids as a percentage of total fat calculated from the questionnaire with the trans isomer composition of adipose aspirates. ${ }^{11}$

\section{Outcome assessment}

We considered as endpoints all incident fatal and nonfatal strokes occurring between the return of the baseline questionnaire and 31 January 2000. A physician blinded to risk factor status reviewed participants' medical records, for which permission was obtained, when incident strokes were reported on a follow up questionnaire. Fatal stroke was reported by next of kin or colleagues or obtained from postal authorities or the national death index. All fatal cases have been confirmed by medical records, autopsy report, or death certificate. We classified cases into ischaemic (embolism or thrombosis), haemorrhagic (subarachnoid and intracerebral), or unknown type of stroke according to the criteria of the national survey of stroke. ${ }^{12}$

\section{Statistical analyses}

We calculated follow up time for each participant from the date of return of the first questionnaire to the date of the first stroke, death, or end of the follow up. We 
divided participants into fifths according to their intake of each type of fat. We calculated incidence rates as the number of events divided by the follow up time in each fifth. We estimated relative risks with rate ratios comparing the incidence of stroke in a particular fifth of dietary intake with that of the lowest fifth. To estimate age and smoking adjusted relative risks and 95\% confidence intervals we used the Mantel-Haenszel method by stratifying data according to age (five year categories) and smoking status. To further adjust for other covariates we used Cox's proportional hazards models with age (months) as the time variable. In addition to determining the effects of each type of fat individually, we examined the possible confounding by intake of other fat subtypes in secondary analyses. Nutrient intakes were adjusted for energy by regression analysis or used as a nutrient density (nutrient/energy), and we included total energy intake in all regression models. We used the Mantel extension test to test for linear trends, ${ }^{13}$ and we included the median values for each fifth in the model as a continuous variable.

To account for changes in diet during the follow up and to best represent long term intake, we used the cumulative average of nutrient intakes derived from all previous food frequency questionnaires. To determine the difference between long term and most recent fat intake, we used the baseline intake and the most recent intake in relation to incidence of stroke. The detail of this method has been previously described. ${ }^{4}$ We used the Keys equation to predict serum cholesterol from dietary intake of cholesterol and saturated and polyunsaturated fat. ${ }^{14}$ As participants were likely to change their diets after they developed some diseases or health conditions, we stopped updating individual dietary information if a participant had diabetes mellitus, coronary heart disease, transient ischaemic attack, peripheral arterial disease, or a diagnosis of hypercholesterolaemia.

\section{Results}

During the 14 year follow up we documented 725 cases, including 455 ischaemic strokes, 125 haemorrhagic strokes, and 145 strokes of unknown type. In both age and smoking adjusted analyses and multivariate analyses, intakes of total fat, animal fat, vegetable fat, saturated fat, monounsaturated fat, polyunsaturated fat, trans unsaturated fat, or cholesterol or the score from the Keys equation were not significantly associated with risk of ischaemic or haemorrhagic stroke. Also, none of the trends across fifths was statistically significant (table 1). After further adjustment for intakes of other fat subtypes, the results were not appreciably altered. In addition, none of the specific types of fat intake was significantly related to risk of total stroke (data not shown).

To evaluate the effects of long term and short term dietary intakes, we examined these associations by using baseline intakes and the most recent intakes separately. The multivariate estimations were similar to those obtained using cumulative average diet, and none of the associations was statistically significant (table 2).

We have reported earlier that intakes of long chain omega 3 fatty acids from seafood were inversely associ- ated with ischaemic but not haemorrhagic stroke. ${ }^{4}$ However, neither total omega 3 nor omega 6 polyunsaturated fatty acid intake was significantly related to ischaemic or haemorrhagic stroke in this study (data not shown).

We further evaluated risk of strokes according to consumption of selected foods rich in fat or cholesterol, including red meat, high fat dairy products, nuts, and eggs. We found no significant associations with ischaemic or haemorrhagic stroke (table 3).

\section{Discussion}

We observed no statistically significant associations in this large cohort between intake of total fat, specific types of fat, or cholesterol and risk of ischaemic, haemorrhagic, or total stroke. In addition, consumption of red meats, high fat dairy products, nuts, or eggs did not seem to be related to risk of stroke.

\section{Strengths and weaknesses of the study}

Our findings are unlikely to be explained by recall or selection bias, because of the prospective nature of the study design and minimal loss to follow up. The results are also unlikely to be due to confounding, as the rela-

Table 2 Relative risks of ischaemic stroke according to intakes of total energy, total fat, specific types of fat, and cholesterol as continuous variables in different models

\begin{tabular}{|c|c|}
\hline Daily nutrient increment & Relative risk $(95 \% \mathrm{CI})^{*}$ \\
\hline \multicolumn{2}{|l|}{ Total energy (400 kcal): } \\
\hline Cumulative average diet & $1.00(0.92$ to 1.08$)$ \\
\hline Most recent diet & $1.01(0.95$ to 1.09$)$ \\
\hline Baseline diet & 0.98 (0.91 to 1.05$)$ \\
\hline \multicolumn{2}{|l|}{ Total fat ( $10 \%$ of energy): } \\
\hline Cumulative average diet & 0.97 (0.80 to 1.17$)$ \\
\hline Most recent diet & 0.97 (0.81 to 1.15$)$ \\
\hline Baseline diet & $1.02(0.87$ to 1.21$)$ \\
\hline \multicolumn{2}{|l|}{ Animal fat ( $10 \%$ energy): } \\
\hline Cumulative average diet & $1.08(0.88$ to 1.32$)$ \\
\hline Most recent diet & $1.03(0.85$ to 1.25$)$ \\
\hline Baseline diet & $1.13(0.94$ to 1.36$)$ \\
\hline \multicolumn{2}{|l|}{ Vegetable fat ( $10 \%$ energy): } \\
\hline Cumulative average diet & 0.85 (0.67 to 1.09$)$ \\
\hline Most recent diet & $0.92(0.74$ to 1.15$)$ \\
\hline Baseline diet & 0.87 (0.70 to 1.09$)$ \\
\hline \multicolumn{2}{|l|}{ Saturated fat ( $10 \%$ energy): } \\
\hline Cumulative average diet & $1.10(0.72$ to 1.68$)$ \\
\hline Most recent diet & 1.01 (0.68 to 1.52$)$ \\
\hline Baseline diet & 1.24 (0.85 to 1.82$)$ \\
\hline \multicolumn{2}{|c|}{ Monounsaturated fat ( $10 \%$ of energy): } \\
\hline Cumulative average diet & 0.93 (0.61 to 1.43 ) \\
\hline Most recent diet & 0.99 (0.67 to 1.46$)$ \\
\hline Baseline diet & 1.01 (0.68 to 1.48$)$ \\
\hline \multicolumn{2}{|c|}{ Polyunsaturated fat ( $5 \%$ of energy): } \\
\hline Cumulative average diet & 0.81 (0.57 to 1.15$)$ \\
\hline Most recent diet & $0.83(0.60$ to 1.15$)$ \\
\hline Baseline diet & $0.87(0.63$ to 1.20$)$ \\
\hline \multicolumn{2}{|c|}{ Trans unsaturated fat ( $2 \%$ of energy): } \\
\hline Cumulative average diet & 0.86 (0.55 to 1.32$)$ \\
\hline Most recent diet & $1.04(0.72$ to 1.51$)$ \\
\hline Baseline diet & $0.80(0.53$ to 1.22$)$ \\
\hline \multicolumn{2}{|c|}{ Cholesterol $(200 \mathrm{mg} / 1000 \mathrm{kcal})$ : } \\
\hline Cumulative average diet & $0.92(0.62$ to 1.36$)$ \\
\hline Most recent diet & 0.84 (0.57 to 1.23$)$ \\
\hline Baseline diet & 1.00 (0.70 to 1.39$)$ \\
\hline
\end{tabular}

${ }^{*}$ Adjusted for covariates listed for multivariate model in table 1 . 
Table 3 Relative risks of stroke (95\% confidence intervals) according to categories of consumption of red meat, high fat dairy products, nuts, and eggs

\begin{tabular}{|c|c|c|c|c|c|c|}
\hline & \multicolumn{5}{|c|}{ Frequency of intake } & \multirow[b]{2}{*}{$P$ for trend } \\
\hline & $<1 /$ week & 1/week & 2-4/week & 5-6/week & $\geq 1 /$ day & \\
\hline \multicolumn{7}{|l|}{ Red meats } \\
\hline \multicolumn{7}{|l|}{ Ischaemic stroke: } \\
\hline No of cases & 21 & 21 & 124 & 62 & 227 & - \\
\hline Adjusted for age and smoking & 1.0 & 0.87 (0.47 to 1.61$)$ & 1.04 (0.65 to 1.66$)$ & 0.89 (0.54 to 1.48$)$ & 1.04 (0.66 to 1.64$)$ & 0.64 \\
\hline Multivariate $^{*}$ & 1.0 & 0.81 (0.43 to 1.49$)$ & 0.94 (0.59 to 1.52$)$ & 0.73 (0.44 to 1.22$)$ & 0.97 (0.60 to 1.55$)$ & 0.57 \\
\hline \multicolumn{7}{|l|}{ Haemorrhagic stroke: } \\
\hline No of cases & 4 & 4 & 29 & 24 & 64 & - \\
\hline Adjusted for age and smoking & 1.0 & 0.96 (0.23 to 3.99$)$ & 1.40 (0.48 to 4.05$)$ & 1.76 (0.58 to 5.36$)$ & 1.56 (0.55 to 4.45$)$ & 0.14 \\
\hline Multivariate $^{*}$ & 1.0 & 0.84 (0.20 to 3.49$)$ & 1.23 (0.42 to 3.57$)$ & $1.71(0.58$ to 5.06$)$ & 1.58 (0.55 to 4.55$)$ & 0.19 \\
\hline \multicolumn{7}{|l|}{ High fat dairy products } \\
\hline \multicolumn{7}{|l|}{ Ischaemic stroke: } \\
\hline No of cases & 18 & 47 & 113 & 48 & 225 & - \\
\hline Adjusted for age and smoking & 1.0 & 1.53 (0.88 to 2.66$)$ & $1.11(0.67$ to 1.84$)$ & 1.01 (0.58 to 1.76$)$ & $1.19(0.73$ to 1.94$)$ & 0.82 \\
\hline Multivariate $^{*}$ & 1.0 & 1.50 (0.86 to 2.62$)$ & $1.03(0.62$ to 1.71$)$ & 0.88 (0.51 to 1.55$)$ & 1.23 (0.74 to 2.03 ) & 0.38 \\
\hline \multicolumn{7}{|l|}{ Haemorrhagic stroke: } \\
\hline No of cases & 5 & 8 & 36 & 12 & 63 & - \\
\hline Adjusted for age and smoking & 1.0 & $1.04(0.34$ to 3.19$)$ & 1.27 (0.49 to 3.28$)$ & 0.83 (0.28 to 2.52$)$ & $1.19(0.47$ to 3.01$)$ & 0.54 \\
\hline Multivariate $^{\star}$ & 1.0 & $0.86(0.27$ to 2.69$)$ & 1.25 (0.48 to 3.27$)$ & $0.87(0.30$ to 2.56$)$ & $1.22(0.47$ to 3.16$)$ & 0.53 \\
\hline \multicolumn{7}{|l|}{ Nuts } \\
\hline \multicolumn{7}{|l|}{ Ischaemic stroke: } \\
\hline No of cases & 105 & 112 & 152 & 36 & 48 & - \\
\hline Adjusted for age and smoking & 1.0 & 1.13 (0.87 to 1.48$)$ & $1.03(0.80$ to 1.32$)$ & 0.95 (0.65 to 1.40$)$ & 0.85 (0.61 to 1.20$)$ & 0.31 \\
\hline Multivariate $^{*}$ & 1.0 & 1.09 (0.83 to 1.43$)$ & 1.01 (0.78 to 1.31$)$ & 0.95 (0.64 to 1.41$)$ & 0.88 (0.61 to 1.26$)$ & 0.30 \\
\hline \multicolumn{7}{|l|}{ Haemorrhagic stroke: } \\
\hline No of cases & 28 & 33 & 38 & 7 & 19 & - \\
\hline Adjusted for age and smoking & 1.0 & 1.22 (0.74 to 2.02$)$ & 0.97 (0.60 to 1.57$)$ & 0.68 (0.30 to 1.57$)$ & 1.32 (0.74 to 2.37$)$ & 0.89 \\
\hline Multivariate $^{*}$ & 1.0 & 1.29 (0.77 to 2.15$)$ & 1.05 (0.63 to 1.74$)$ & 0.74 (0.31 to 1.72$)$ & 1.29 (0.69 to 2.42$)$ & 0.82 \\
\hline \multicolumn{7}{|l|}{ Eggs } \\
\hline \multicolumn{7}{|l|}{ Ischaemic stroke: } \\
\hline No of cases & 134 & 93 & 167 & 30 & 24 & - \\
\hline Adjusted for age and smoking & 1.0 & 0.83 (0.64 to 1.08$)$ & 0.87 (0.69 to 1.09 ) & $1.14(0.76$ to 1.70$)$ & 0.88 (0.56 to 1.37$)$ & 0.81 \\
\hline Multivariate $^{*}$ & 1.0 & 0.83 (0.63 to 1.09 ) & 0.86 (0.68 to 1.09$)$ & 1.23 (0.81 to 1.87$)$ & 1.09 (0.69 to 1.71$)$ & 0.35 \\
\hline \multicolumn{7}{|l|}{ Haemorrhagic stroke: } \\
\hline No of cases & 29 & 35 & 47 & 8 & 2 & - \\
\hline Adjusted for age and smoking & 1.0 & 1.39 (0.85 to 2.28$)$ & 1.14 (0.73 to 1.81$)$ & 1.45 (0.68 to 3.09 ) & 0.39 (0.10 to 1.59$)$ & 0.64 \\
\hline Multivariate $^{*}$ & 1.0 & 1.47 (0.88 to 2.45$)$ & $1.17(0.72$ to 1.90$)$ & 1.54 (0.67 to 3.50$)$ & 0.32 (0.07 to 1.37$)$ & 0.34 \\
\hline
\end{tabular}

tive risk estimates did not materially change after simultaneous adjustment for the potential confounding variables. However, as in any observational study, residual confounding from some unknown factors could not be excluded.

The food frequency questionnaire that we used in the dietary assessment has been previously evaluated as a reasonable reflection of long term diet, including fat intakes. ${ }^{7}$ In addition, we reduced error in dietary assessment by using repeated measurements. The questionnaire's validity is further supported by the fact that it has predicted risk of coronary heart disease in this cohort. ${ }^{15}$ Participants might change their diets after developing some diseases that predispose them to stroke. After the dietary recommendation in the past decades, the most likely changes would be reduction in total fat, saturated fat, and cholesterol intakes. These dietary changes would dilute a possible positive association between these nutrients and risk of stroke. To reduce bias from this source, we excluded men with cardiovascular diseases or diabetes mellitus at baseline and stopped updating individual dietary information once a participant reported any cardiovascular disease, diabetes, or hypercholesterolaemia during the follow up period. The fact that the associations remained similar when we used baseline diet, most recent diet, or cumulative average diet further suggested that the observed associations were unlikely to be substantially attenuated.

\section{Ischaemic stroke}

Saturated fat intake has been found to be positively related to carotid artery wall thickness, a marker of atherosclerosis and a potential risk factor for stroke. ${ }^{16}$ Polyunsaturated fat intake was inversely associated with this marker. However, epidemiological data on dietary fat and risk of stroke have produced inconsistent results. Whereas saturated fat intake was positively correlated with total mortality from stroke in an ecological study, ${ }^{17}$ and the results of several prospective studies have supported beneficial effects of long chain omega 3 polyunsaturated fatty acids, $\alpha$ linolenic acid, and linoleic acid on ischaemic stroke, ${ }^{4-6}$ opposite results were reported from the Framingham heart study. ${ }^{2}$ In that study total fat, saturated fat, and monounsaturated fat, but not polyunsaturated fat, were inversely associated with risk of ischaemic stroke.

Although ischaemic heart disease and stroke share many of the same risk factors, the association of blood cholesterol with stroke remains controversial. A metaanalysis including 45 prospective cohorts found no association between blood cholesterol and stroke. ${ }^{18}$ 


\section{What is already known on this topic}

The associations between different types of fat and coronary heart disease do not seem to apply to stroke

Ecological data indicate that dietary fat intake is inversely related to risk of stroke

\section{What this study adds}

Intake of total fat, cholesterol, or major specific types of fat was not associated with risk of stroke

Consumptions of red meats, high fat dairy products, nuts, and eggs were also not appreciably related to risk of stroke

However, most studies did not distinguish ischaemic stroke from haemorrhagic stroke, which contributes approximately $20 \%$ of all strokes in Western countries, and this would probably dilute any association between blood cholesterol and ischaemic stroke. No significant association between reduction in blood cholesterol and risk of stroke was reported in an overview of trials of cholesterol lowering treatment involving more than 36000 patients. $^{19}$ However, in recent trials of cholesterol lowering treatment in patients with cardiovascular disease, the incidence of stroke was reduced in the treated groups. ${ }^{20}$ Overall, it seems that serum lipid concentration is not a strong predictor of total stroke, probably because a substantial proportion of ischaemic strokes are caused by embolism or other mechanisms that are not directly related to atherosclerosis. In addition, nitric oxide and inflammation may play important roles in the pathogenesis of ischaemic stroke,,$^{21} 22$ and the findings of the beneficial effects of unsaturated fatty acids on ischaemic stroke may be in part due to their favourable effects on platelet aggregation and endothelial function. ${ }^{4-6} 2324$

\section{Haemorrhagic stroke}

The association between dietary fat intake and risk of haemorrhagic stroke is far from clear. In the nurses' health study, Iso et al observed an inverse association between risk of intraparenchymal haemorrhagic stroke and intake of saturated fat or trans unsaturated fat but no associations with total fat, polyunsaturated fat, monounsaturated fat, or dietary cholesterol. ${ }^{3}$ Although we did not observe any significant association between dietary fat intake and risk of haemorrhagic stroke, we could not exclude any important association because of the modest number of cases of haemorrhagic stroke. Further studies are needed.

\section{Conclusion}

Our findings from this large cohort of middle aged US male healthcare professionals without a history of cardiovascular disease or diabetes mellitus indicate that intakes of total fat, specific types of fat, or dietary cholesterol do not seem to be related to the development of stroke.

We thank the participants of the health professional follow up study for their continuing participation and cooperation.

Contributors: KH contributed to the study concept and design and the analysis and interpretation of the data and drafted the manuscript. AM contributed to data analysis and interpretation. EBR contributed to the study concept and design, analysis and interpretation of the data, and funding. BAR contributed to data analysis and interpretation and editing of the manuscript. MJS contributed to the study concept and design, data analysis and interpretation, and editing of the manuscript. WCW contributed to the study concept and design, analysis and interpretation of the data, editing of the manuscript, and funding. AA contributed to the study concept and design, analysis and interpretation of the data, funding, and editing of the manuscript and supervised the study. AA is the guarantor of this study.

Funding: This work was supported by the research grant HL35464 and CA55075 from the National Institutes of Health. $\mathrm{KH}$ was a recipient of the Arthur T Lyman and Henry S Grew memorial scholarship and the Stares fellowship from Harvard University when he conducted this study.

Competing interests: None declared.

Ethical approval: Harvard School of Public Health institutional review board approved the study design, data collection, and analysis plan.

1 Hu FB, Stampfer MJ, Manson JE, Rimm E, Colditz GA, Rosner BA, et al. Dietary fat intake and the risk of coronary heart disease in women. NEngl J Med 1997;337:1491-9.

2 Gillman MW, Cupples LA, Millen BE, Ellison RC, Wolf PA. Inverse association of dietary fat with development of ischemic stroke in men. JAMA 1997;278:2145-50.

3 Iso H, Stampfer MJ, Manson JE, Rexrode K, Hu F, Hennekens CH, et al. Prospective study of fat and protein intake and risk of intraparenchymal hemorrhage in women. Circulation 2001;103:856-63.

4 He K, Rimm EB, Merchant A, Rosner BA, Stampfer MJ, Willett WC, et al. Fish consumption and risk of stroke in men. JAMA 2002;288:3130-6.

5 Simon JA, Fong J, Bernert JT Jr, Browner WS. Serum fatty acids and the risk of stroke. Stroke 1995;26:778-82.

6 Iso H, Sato S, Umemura U, Kudo M, Koike K, Kitamura A, et al. Linolei acid, other fatty acids, and the risk of stroke. Stroke 2002;33:2086-93.

7 Willett WC, Sampson L, Stampfer MJ, Rosner B, Bain C, Witschi J, et al. Reproducibility and validity of a semiquantitative food frequency questionnaire. Am J Epidemiol 1985;122:51-65.

8 Enig MG, Pallansch LA, Sampugna J, Keeney M. Fatty acid composition of the fat in selected food items with emphasis on trans components. J Am Oil Chem Soc 1983;60:1788-95.

9 Slover HT, Thompson RHJ, Davis CS, Merola GV. Lipids in margarines and margarine-like foods. J Am Oil Chem Soc 1985;62:775-86.

10 Rimm EB, Giovannucci EL, Stampfer MJ, Colditz GA, Litin LB, Willett WC. Reproducibility and validity of an expanded self-administered semiquantitative food frequency questionnaire among male health professionals. Am J Epidemiol 1992;135:1114-26 (discussion 1127-36).

11 Hunter DJ, Rimm EB, Sacks FM, Stampfer MJ, Colditz GA, Litin LB, et al. Comparison of measures of fatty acid intake by subcutaneous fat aspirate, food frequency questionnaire, and diet records in a free-living population of US men. Am J Epidemiol 1992;135:418-27.

12 Walker AE, Robins M, Weinfeld FD. The national survey of stroke: clinical findings. Stroke 1981;12(2 pt 2 suppl 1):I13-44.

13 Mantel N. Chi-square tests with one degree of freedom: extensions of the Mantel-Haenszel procedure. J Am Stat Assoc 1963;58:690-700.

14 Keys A, Anderson JT, Grande F. Serum cholesterol response to changes in the diet. I. Iodine value of dietary fat versus 2S-P. Metabolism $1965 ; 14: 747-58$

15 Ascherio A, Rimm EB, Giovannucci EL, Spiegelman D, Stampfer M, Willett WC. Dietary fat and risk of coronary heart disease in men: cohort follow up study in the United States. BMJ 1996;313:84-90.

16 Tell GS, Evans GW, Folsom AR, Shimakawa T, Carpenter MA, Heiss G. Dietary fat intake and carotid artery wall thickness: the atherosclerosis risk in communities (ARIC) study. Am J Epidemiol 1994;139:979-89.

17 Sasaki S, Zhang XH, Kesteloot H. Dietary sodium, potassium, saturated fat, alcohol, and stroke mortality. Stroke 1995;26:783-9.

18 Prospective Studies Collaboration. Cholesterol, diastolic blood pressure, and stroke: 13,000 strokes in 450,000 people in 45 prospective cohorts. Lancet 1995;346:1647-53.

19 Hebert PR, Gaziano JM, Hennekens CH. An overview of trials of cholesterol lowering and risk of stroke. Arch Intern Med 1995;155:50-5.

20 Heart Protection Study Collaborative Group. MRC/BHF heart protection study of cholesterol lowering with simvastatin in 20,536 high-risk individuals: a randomised placebo-controlled trial. Lancet 2002;360:7-22.

21 Keaney JF Jr, Vita JA. Atherosclerosis, oxidative stress, and antioxidant protection in endothelium-derived relaxing factor action. Prog Cardiovasc Dis 1995;38:129-54.

22 LaBiche R, Koziol D, Quinn TC, Gaydos C, Azhar S, Ketron G, et al. Presence of Chlamydia pneumoniae in human symptomatic and asymptomatic carotid atherosclerotic plaque. Stroke 2001:32:855-60.

23 Driss F, Vericel E, Lagarde M, Dechavanne M, Darcet P. Inhibition of platelet aggregation and thromboxane synthesis after intake of small amount of icosapentaenoic acid. Thromb Res 1984;36:389-96.

24 De Caterina R, Cybulsky MI, Clinton SK, Gimbrone MA Jr, Libby P. The omega-3 fatty acid docosahexaenoate reduces cytokine-induced expression of proatherogenic and proinflammatory proteins in human endothelial cells. Arterioscler Thromb 1994;14:1829-36.

(Accepted 18 July 2003) 